\title{
Fabrication of 2D Manganese Tungstate Nanosheets for the Mitigation of Antipsychotic Drug Chlorpromazine
}

\author{
J. Vinoth Kumar, D. Sivaganesh, M. Arunpandian, E. R. Nagarajan
}

\begin{abstract}
In this work, we developed a novel and superior two dimensional manganese tungstate nanosheets (MnW NSs) photocatalyst for the degradation of environmentally toxic antipsychotic drug chlorpromazine (CPZ) under visible light illumination. The MnW NSs were fabricated through the simple microwave assisted hydrothermal route without the addition of other solvents. The surface topology and crystalline nature of the material was investigated by using numerous spectroscopic techniques. Fascinatingly, the MnW NSs exhibited superior photocatalytic activity towards the degradation of antipsychotic pharmaceutical drug under visible light irradiation.
\end{abstract}

Keywords: Visible-light, Photocatalyst, Pharmaceuticals, photodegradation.

\section{INTRODUCTION}

In the past days, pharmaceutical drugs are most widely used to cure or prevent the known and unknown diseases for the both animal and human beings. However, the over long time usage of drugs may leads to reaches the soil and water environment through the surplus disposal of hospitals and pharmaceutical industries. The occurrence of drugs in soil and water system cause's serious health impacts such as mutagenic, carcinogenic, androgenic, chronic toxicity and so forth [1,2]. Moreover, soil systems can also affected by the drugs. For these reasons, complete degradation of drugs is a crucial phenomenon to the researchers. Various methods including coagulation, adsorption, fluctuation, osmosis and so forth, have been available for the detoxification of organic pollutants. But, the aforementioned techniques have some major problems such as high cost and produce secondary hazardous by-products. However, photocatalysis route could provide simple, green and low cost which degrades toxic pollutants into less toxic products $[3,4]$.

Recently, tungsten combined metal oxide have been a key in numerous science, engineering and technological

\footnotetext{
Revised Manuscript Received on December 17, 2019

* Correspondence Author

E.R. Nagarajan*, Department of Chemistry, Nanomaterials Laboratory, International Research Centre, Kalasalingam Academy of Research and Education, Krishnankoil-626126, Tamil Nadu, India. Email: nagarajanklu@gmail.com

J. Vinoth Kumar, Department of Chemistry, Nanomaterials Laboratory, International Research Centre, Kalasalingam Academy of Research and Education, Krishnankoil-626126, Tamil Nadu, India. Email: vinothchem7@gmail.com

D. Sivaganesh, Department of Physics, International Research Centre, Kalasalingam Academy of Research and Education, Krishnankoil-626126, Tamil Nadu, India. Email: ganesh.siva650@gmail.com

M. Arunpandian, Department of Chemistry, Nanomaterials Laboratory, International Research Centre, Kalasalingam Academy of Research and Education, Krishnankoil-626126, Tamil Nadu, India. Email: arunpandiantt126@gmail.com
}

applications because of their superior optical, electrical, mechanical and chemical properties [5,6]. In more specifically, manganese $(\mathrm{Mn})$ combined tungstate have great attention in various fields including electrochemical sensors, energy storage, Li-ion batteries, LED and photocatalysis applications due to their very good physical and chemical properties [7,8]. Therefore, synthesis of well-defined nanostructured manganese tungstate with good crystalline purity and huge active surface area prepared via cost-effect, scalable and easy route is a major concern to the research area.

Due to the aforesaid interesting tasks, we made an effort for the design of nanosheets like $\mathrm{MnWO}_{4}$ through simple precipitation technique with the use of urea. The as-synthesized $\mathrm{MnWO}_{4}$ nanosheets were affirmed by various spectroscopic techniques and used as a photocatalyst for the degradation of antipsychotic drug chlorpromazine under visible light irradiation.

\section{EXPERIMENTAL SECTION}

\section{A. Materials}

Manganese chloride dihydrate $\left(\mathrm{MnCl}_{2} \cdot 2 \mathrm{H}_{2} \mathrm{O}\right)$, sodium tungstate $\left(\mathrm{Na}_{2} \mathrm{WO}_{4}\right)$, urea and chlorpromazine chemicals were purchased from Merck chemicals, India.

\section{B. Synthesis of sheet-like $\mathrm{MnWO}_{4}$}

In a typical recipe, $0.2 \mathrm{M} \mathrm{Na}_{2} \mathrm{WO}_{4}$ and $0.1 \mathrm{M} \mathrm{MnCl}_{2} \cdot 2 \mathrm{H}_{2} \mathrm{O}$ were dispersed in $60 \mathrm{~mL}$ of distilled water under constant stirring for $30 \mathrm{~min}$. Then, $0.5 \mathrm{M}$ urea was added to the above solution and stirred for $1 \mathrm{~h}$. After that, the obtained brown color products were washed copious amount of water and ethanol to eliminate the un-reacted impurities and dried at $50^{\circ} \mathrm{C}$ for whole night. Finally, the dried products were grinded into a fine powder and calcined at $400^{\circ} \mathrm{C}$ for $2 \mathrm{~h}$ in an air atmosphere contained muffle furnace. The overall synthesis route for the fabrication of $\mathrm{MnWO}_{4}$ is represented in Scheme 1. 


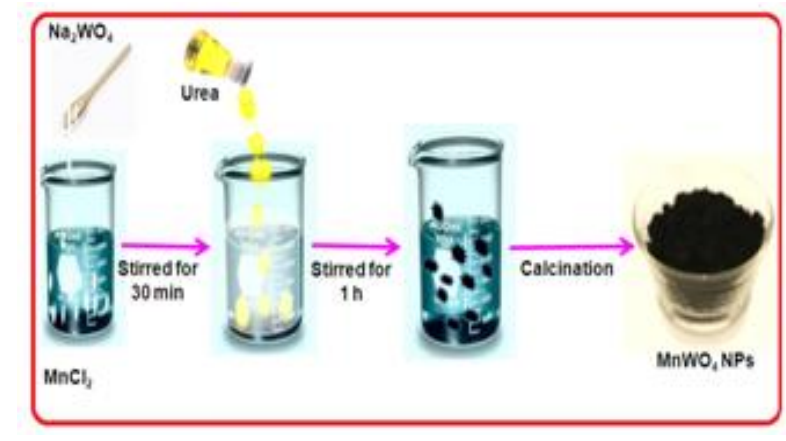

Scheme 1. Schematic representation for the fabrication of $\mathrm{MnWO}_{4}$ nanoparticles.

\section{RESULT AND DISCUSSION}

The crystalline nature of the material was identified by X-ray diffraction (XRD) analysis. Fig. 1 portrayed the XRD pattern of as-synthesized $\mathrm{MnWO}_{4}$ material. As can be seen, all the diffraction peaks can be assigned to the monoclinic phase $\mathrm{MnOW}_{4}$, which are well matched to their standard JCPDS File number 80-0152.

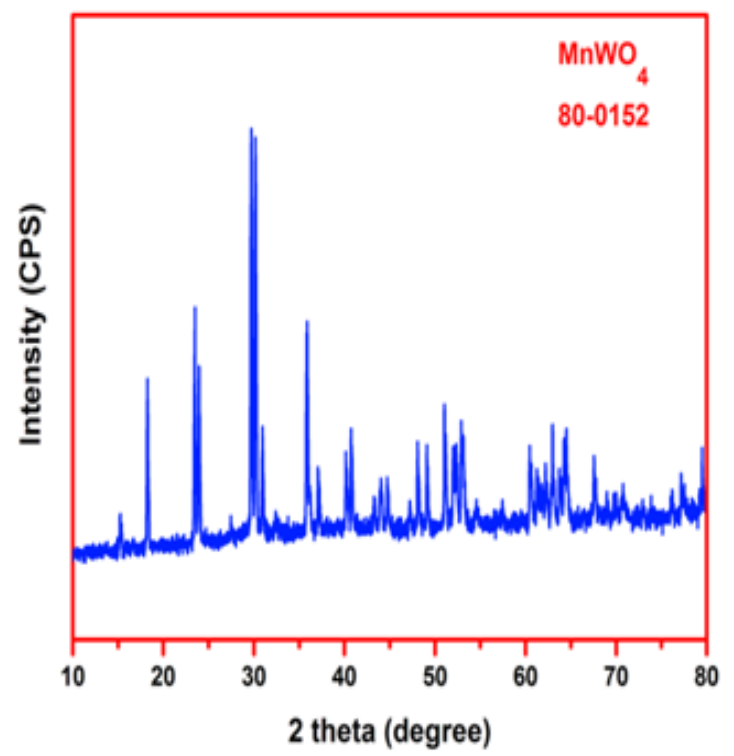

Fig. 1. XRD pattern of as-synthesized $\mathrm{MnWO}_{4}$.

The morphology of the as-synthesized material was observed by scanning electron microscopy (SEM) analysis and the results are represented in Fig. 2 (A\&B). The different magnification SEM micrographs clearly displayed that the as-synthesized $\mathrm{MnWO}_{4}$ material have the nanosheets like structures with very rough surfaces. The average diameter and the length of the $\mathrm{MnWO}_{4}$ nanosheets is approximately to be $1 \mu \mathrm{m}$ and $600 \mathrm{~nm}$, respectively.

Moreover, EDX spectrum could provide the clear information about the elemental composition of the material and shown in Figure 3. It unambiguously portrayed that the appearance of manganese (Mn), tungsten (W) and Oxygen (O) elements without impurities.
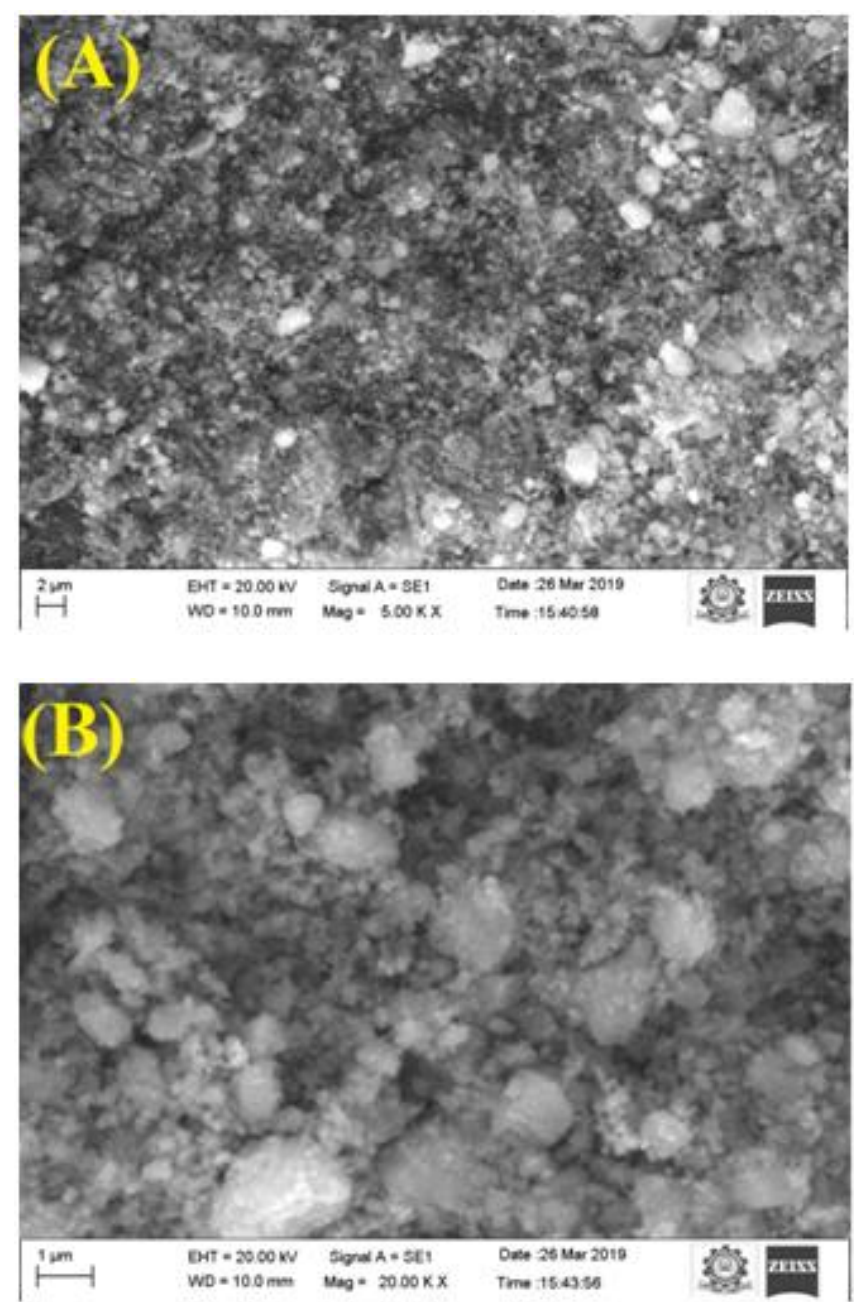

Fig. 2. (A\&B) Different magnification SEM micrographs of as-synthesized $\mathrm{MnWO}_{4}$.

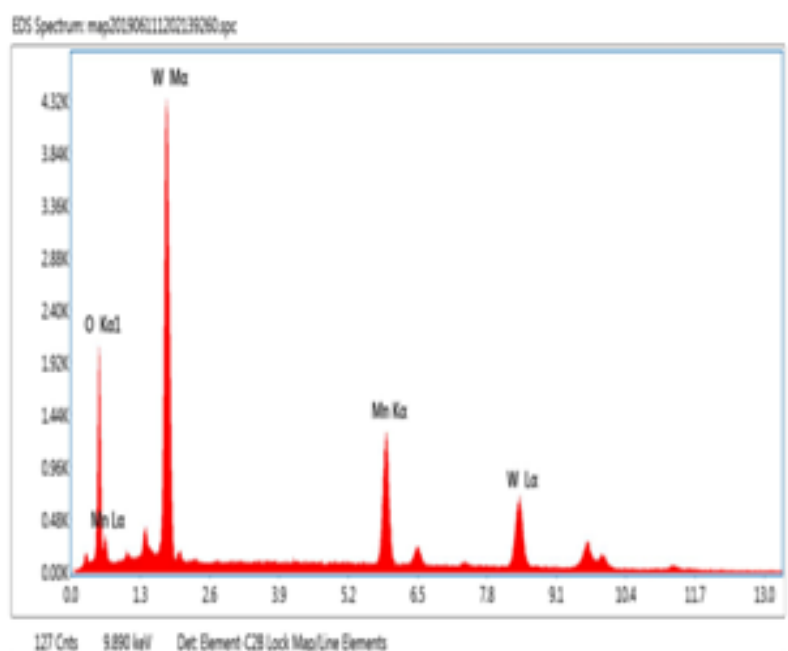

Fig. 3. EDX spectrum of $\mathrm{MnWO}_{4}$

\section{A. Photocatalytic Activity}

The photocatalytic performance of as-synthesized $\mathrm{MnWO}_{4}$ was carried out towards the removal of $\mathrm{CPZ}$ drug under visible light. Fig. 4 demonstrated that the maximum intensity peak of CPZ at $307 \mathrm{~nm}$ was diminishes linearly upon increasing irradiation time.

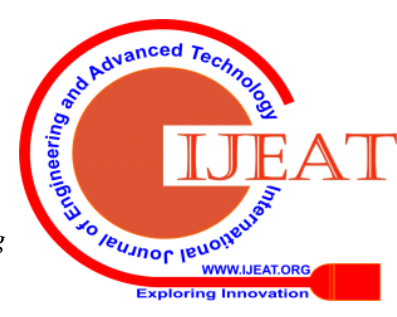


After $70 \mathrm{~min}$, the peak tends to reach almost equal to zero, implied that the complete degradation of CPZ by $\mathrm{MnWO}_{4}$.

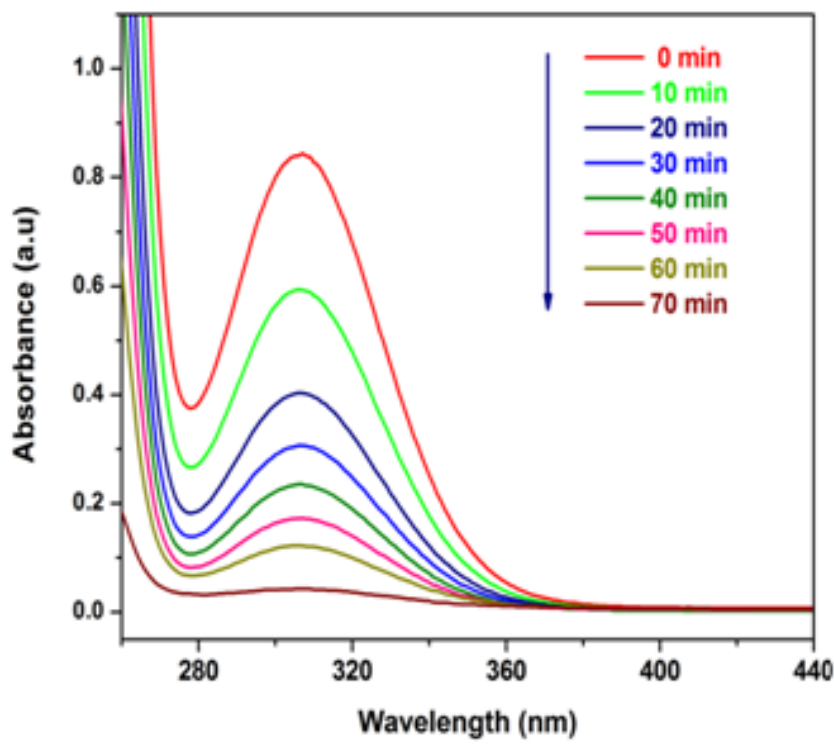

Fig. 4.Time-dependent UV-visible spectrum of CPZ photodegradation by $\mathrm{MnWO}_{4}$ under visible light irradiation.

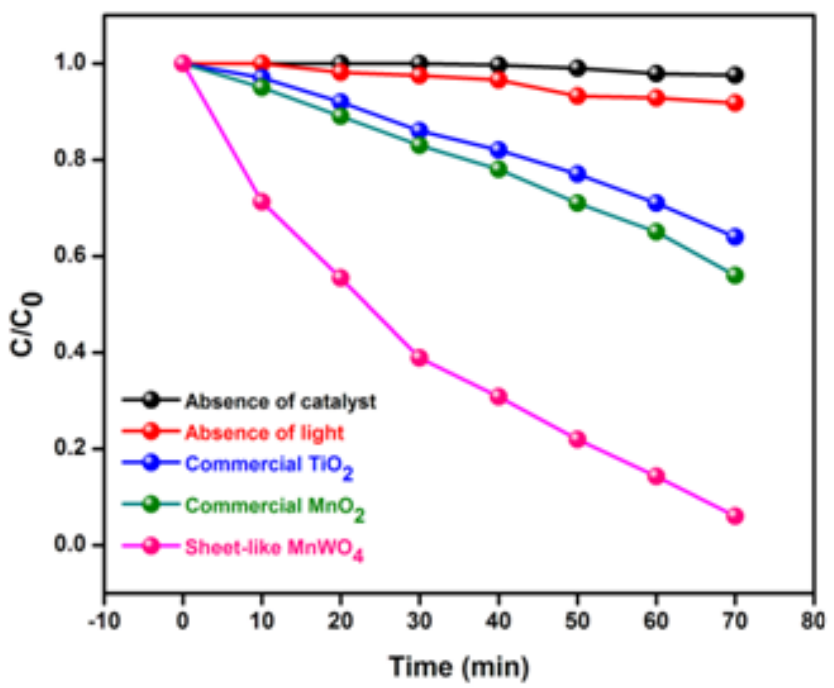

Fig. 5. Photodegradation of CPZ solution over the different catalysts and dark conditions.

More interestingly, the as-synthesized $\mathrm{MnWO}_{4}$ exhibited excellent photocatalytic performances when compared to commercial $\mathrm{TiO}_{2}$ and $\mathrm{MnO}_{2}$, as depicted in Fig. 5.

\section{CONCLUSION}

In conclusion, new and superior sheet-like $\mathrm{MnWO}_{4}$ photocatalyst was developed by simple precipitation route and characterized in detail. Interestingly, the sheet-like $\mathrm{MnWO}_{4}$ exhibited superior photocatalytic activity towards the detoxification of CPZ under solar light. This work crates a new idea for the fabrication of binary metal oxides for environmental applications.

\section{ACKNOWLEDGMENT}

We are grateful to thank the Kalasalingam Academy of Research and Education, Tamil Nadu, India for providing research facilities.

\section{REFERENCES}

1. J. V. Kumar, R. Karthik, Shen-Ming Chen, K. Natarajan, K. Chelladurai, C. C. Yang, V. Muthuraj, "3D Flower-Like Gadolinium Molybdate Catalyst for Efficient Detection and Degradation of Organophosphate Pesticide (Fenitrothion)," ACS Appl. Mater. Interfaces, 10 (2018) 15652-15664.

2. J. V. Kumar, R. Karthik, Shen-Ming Chen, V. Muthuraj, C. Karuppiah, "Fabrication of potato-like silver molybdate microstructures for photocatalytic degradation of chronic toxicity ciprofloxacin and highly selective electrochemical detection of H2O2," Sci. Rep., 6 (2017) 34149.

3. R. Karthik, J. V. Kumar, S. M. Chen, P. S. Kumar, V. Selvam, V. Muthuraj, "A selective electrochemical sensor for caffeic acid and photocatalyst for metronidazole drug pollutant - A dual role by rod-like SrV2O6," Sci. Rep., 7 (2017) 7254.

4. Y. P. Bhoi, A. K. Nayak, S. K. Gouda, B. G. Mishra, "Photocatalytic mineralization of carbendazim pesticide by a visible light active novel type-II $\mathrm{Bi} 2 \mathrm{~S} 3 / \mathrm{BiFeO} 3$ heterojunction photocatalyst". Catal. Commun. 114 (2018) 114-119.

5. D. Jornet, M. A. Castillo, M. C. Sabater, R. Tormos, M. A. Miranda, "Photodegradation of carbendazim sensitized by aromatic ketones" J. Photochem. Photobiol. A. 256 (2013) 36-41.

6. K. Adib, M. Rahimi-Nasrabadi, Z. Rezvani, S. M. Pourmortazavi, F. Ahmadi, H. R. Naderi, M. R. Ganjali, "Facile chemical synthesis of cobalt tungstates nanoparticles as high performance supercapacitor"J. Mater. Sci. Mater. Electron. 227, (2016) 4541-4550.

7. J. Vinoth Kumar, R. Karthik, S. M. Chen, P. Balasubramanian, V. Muthuraj, V. Selvam, "A novel cerium tungstate nanosheets modified electrode for the effective electrochemical detection of carcinogenic nitrite ions" Electroanalysis, 29 (2017) 2385-2394.

8. P. Sundaresan, A. Krishnapandi, S. M. Chen, "Design and investigation of ytterbium tungstate nanoparticles: An efficient catalyst for the sensitive and selective electrochemical detection of antipsychotic drug chlorpromazine" J. Taiwan. Inst. E. 96 (2019) 509-519

\section{AUTHORS PROFILE}

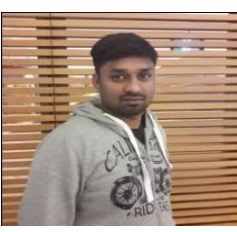

J. Vinoth Kumar is a Post-doctoral fellow at Kalasalingam Academy of Research and Education, Krishnankoil, India. He got his Ph.D Degree from Madurai Kamaraj University, Madurai, India. He is interested in synthesis of nanomaterials for photocatalysis and electrocatalysis applications.

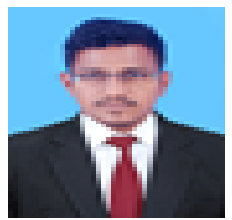

D. Sivaganesh is a Ph.D student at Kalasalingam Academy of Research and Education, India. His research interest is in structural and photoluminescence properties of phosphor materials.

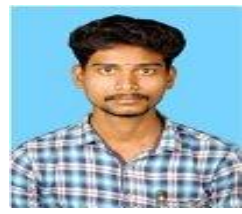

M. Arunpandian is a Ph.D student at Kalasalingam Academy of Research and Education, India. His research interest is in photocatalytic properties of rare earth attached metal oxides composite materials.

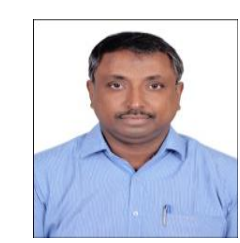

E.R. Nagarajan works as Associate Professor, Department of Chemistry, Kalasalingam Academy of Research and Education, Krishnankoil, Tamil Nadu, India. He received his Ph.D degree at Anna University, Chennai, India. With a research in the applications of polymeric materials, co-ordination

compounds, photocatalysis and electrochemical applications.

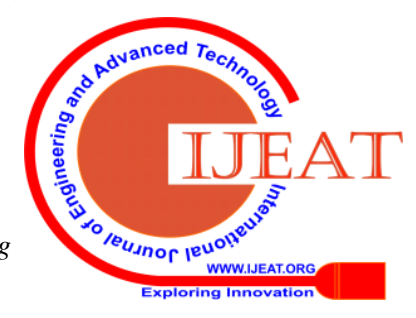

